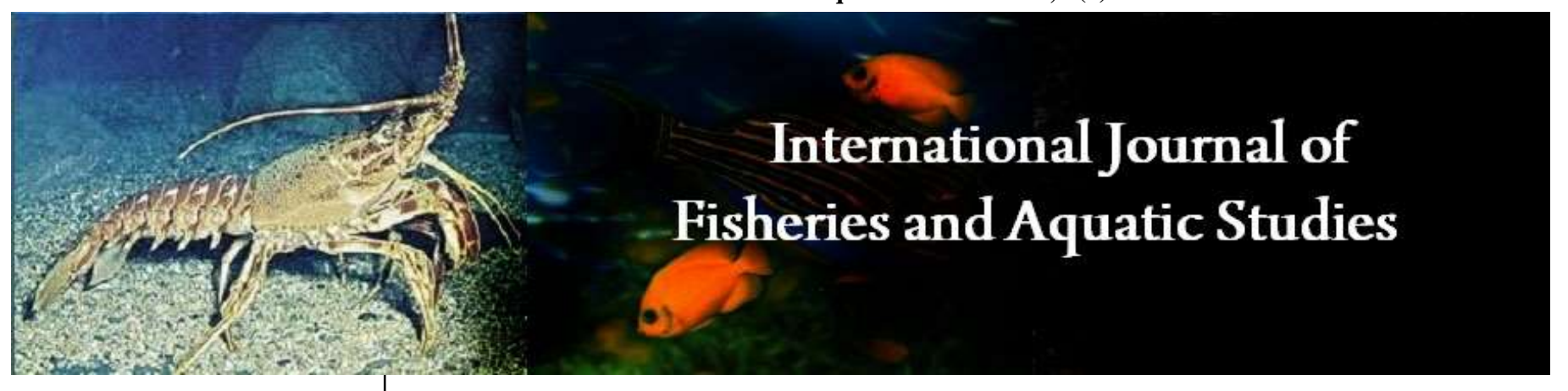

E-ISSN: 2347-5129

P-ISSN: 2394-0506

(ICV-Poland) Impact Value: 5.62

(GIF) Impact Factor: 0.549

IJFAS 2020; 8(6): 181-186

(C) 2020 IJFAS

www.fisheriesjournal.com

Received: 03-09-2020

Accepted: 12-10-2020

Kandasami Nimalan

Department of Civil Engineering,

S.A. Engineering College,

Chennai, Tamil Nadu, India

Muniappan Thanikachalam

Department of Civil Engineering,

S.A. Engineering College,

Chennai, Tamil Nadu, India

Tune Usha

National Centre for Coastal

Research, NIOT Campus,

Pallikaranai, Chennai, Tamil

Nadu, India

Corresponding Author:

Kandasami Nimalan

Department of Civil Engineering,

S.A. Engineering College,

Chennai, Tamil Nadu, India

\section{Estimating the fractional abundance of coral reef benthic compositions using linear spectral unmixing}

\author{
Kandasami Nimalan, Muniappan Thanikachalam and Tune Usha
}

DOI: $\underline{\text { https://doi.org/10.22271/fish.2020.v8.i6c.2375 }}$

\section{Abstract}

The present work is focused on providing the application of linear spectral unmixing technique to Landsat-8 images of Operational Land Imager (OLI) bands in coral reef environment at Gulf of Mannar (GoM) islands along the coast of Tamilnadu, India. The spectral characteristics of benthic compositions namely sand, seagrass, branched corals and mass corals in the GoM are recorded in-situ using RAMSESTriOS Hyperspectral radiometer and the signatures recorded from in-situ have been used as input for linear spectral unmixing technique. The results of linear spectral unmixing provide the fractional abundances of coral reef benthic communities in the Islands of GoM region. Such maps can be used to characterize the landscape structure and composition of reefs, which can in turn be linked to environmental and human impacts. This kind of approaches is cost-effective and acts as a valuable tool for the evaluation and periodical monitoring of coral reef community.

Keywords: Coral reef. Landsat-8, fractional abundance, Gulf of Mannar, spectral unmixing

\section{Introduction}

Monitoring changes in the distribution and abundance of coral reef species is one of the important aspects of coral reef ecology. Generally, the amount of; coral cover, disease monitoring, distribution and their abundance is assessed in field surveys using quadrat; random point sampling; photo and video transect techniques ${ }^{[17]}$. But, this kind of field surveying methods are costly, time consuming and labour intensive. Hence, this makes the field surveying methods as unfeasible for continuous monitoring and management of coral reefs, especially in larger areas. Remotely sensed imagery can be act as a tool for quantitative and systematic monitoring of coral reef at broad synoptic scale ${ }^{[26]}$ and many studies have explored the potential of remote sensing in mapping, monitoring and finding the abundance of coral reefs and their benthic compositions $[1,4,8,10,11,14,21]$. The current options for satellite based coral reef mapping and monitoring is dominated by high spatial resolution multispectral instruments and moderate resolution instruments ${ }^{[12]}$. High spatial resolution images offer many benefits, and these kinds of images are widely used for mapping of coral reefs at local levels ${ }^{[27]}$. However, the expense of high resolution satellite imagery and infrequency of data acquisition, make it unsuitable for repeated monitoring of coral reefs. When it comes to moderate resolution instruments, the Landsat series has produced some useful results [2]. Landsat- 8 in particular, has good capability for techniques based on radiative transfer models [7] and also, the Landsat series provides a continuous datasets from early 1980's ${ }^{[5]}$ and freely available data of them provides the possibilities for routine monitoring and management of coral reefs. The signal detected by a sensor into a single pixel is frequently a combination of numerous disparate signals. Due to the high level of spatial heterogeneity, complex of coral reef environments, even at a sub-metre scale, an image pixel from a high spatial resolution satellite image sensor (The spatial resolution of satellite image used for this study i.e., Landsat8 is $30 \mathrm{~m}$ ) will mostly be comprised of multiple coral reef benthos and substrate types, resulting in a mixed end-member spectral reflectance signature ${ }^{[15]}$. An effective approach to find the relative abundance of coral reef benthos is to use the linear spectral unmixing technique. Linear Spectral Unmixing is a tool to decompose the pixels into the abundance of its components. The reflectance at each pixel of the image is assumed to be a linear combination of the reflectance of each endmember present within the pixel. The number of endmembers must be less than the number of spectral bands and all of the endmembers in the image must be used. 
The efficiency of linear spectral unmixing techniques has been evaluated for small-scale assemblages of coral reef substrata by Goodman and Ustin \& Hedley et al. Sarah Hamylton have used Hyperspectral data to estimate the coverage of coral reef benthic communities using linear spectral unmixing. This current research utilises the Linear Spectral unmixing to the Landsat- 8 image in-order to determine the relative abundance of benthic compositions in various study sites based on the characteristics of spectra collected from in-situ.

\section{Study Area}

Government of India has established the Gulf-of-Mannar Biosphere Reserve, in 1989, is one among the four major reef areas in India, located on the South-Eastern coast. Reefs in the GoM are developed around 21 uninhabited islands that lies between the latitude of $8^{0} 47^{\prime} \mathrm{N}$ to $9^{0} 15^{\prime} \mathrm{N}$ and longitude of $78^{\circ} 12^{\prime} \mathrm{E}$ to $79^{\circ} 14^{\prime} \mathrm{E}$ covering an area of 623 ha along the 140 $\mathrm{km}$ stretch between Tuticorin and Rameswaram in the state of Tamil Nadu, India.

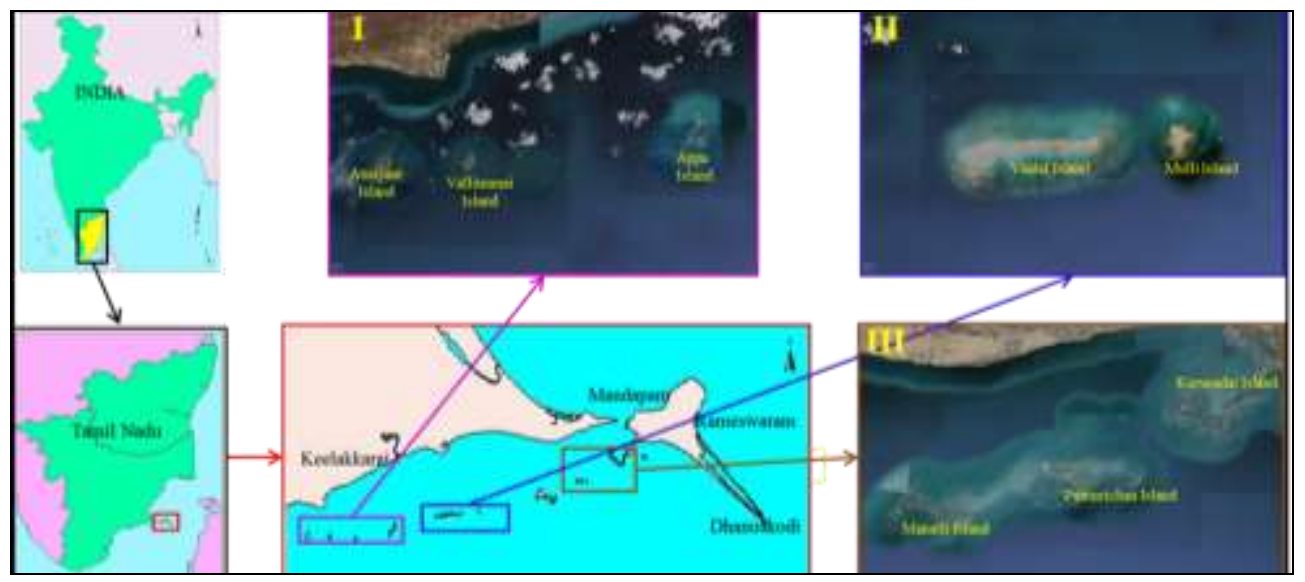

Fig 1: Location of Gulf of Mannar in Tamil Nadu, India, and a Google earth image depicting the study sites of I, II \& III.

As many as 133 species of corals and its reef of fringing and patchy type are present at $5 \mathrm{~m}$ depth around the islands. This area is remarkable for its faunal and floral wealth, especially the coral reefs and its associates ${ }^{[24]}$. Fig.1 shows the Location of GoM in Tamil Nadu, India, and a Google earth image depicting the study sites of I, II \& III.

\section{Materials and Methods 3.1 Processing Overview}

An overview of the processing procedure is described in Fig.2. This approach for deriving fractional abundance of coral reef benthic communities using landsat-8 imagery includes pre-processing routines, Such as atmospheric and water column correction. The atmospherically corrected images doesn't reveal any significant sun-glint effect, therefore no sun-glint correction is applied to the images.

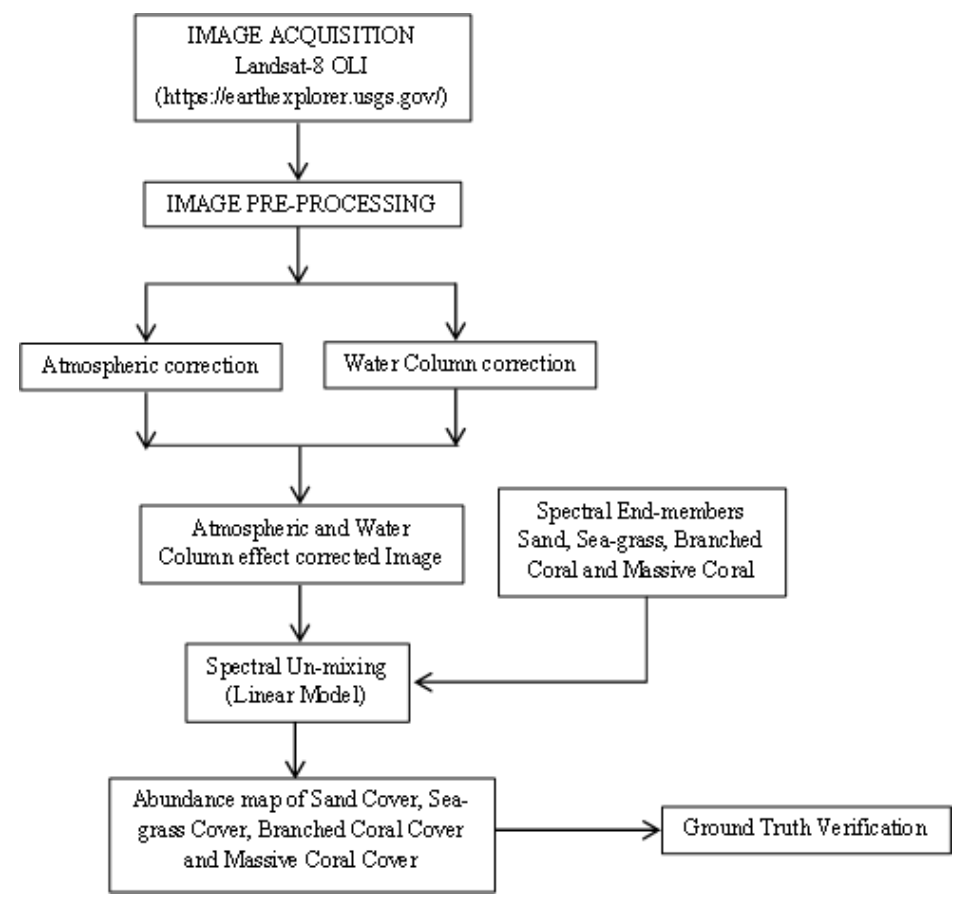

Fig 2: Overview of Image processing procedure.

The spectral end-members representing carbonate sand, seagrass, branched coral and massive corals recorded from insitu are used as input for spectral un-mixing using linear model for deriving the per-pixel contribution of each of the spectral end-members, and thus an abundance fraction map of those benthic compositions. 


\subsection{Landsat Imagery}

Landsat imagery of the study area was acquired on two different dates; the image of Group-I and Group-III was acquired on 25 March 2017 and the image of Group-II was acquired on 05 February 2017 by NASA's Landsat- 8 satellite mission with OLI payload. The satellite images were downloaded from United States Geographical Survey website (https://earthexplorer.usgs.gov/).

\subsection{Image Pre-processing}

The total signal received by satellite sensors are dominated by radiance contributed through atmospheric scattering ${ }^{[27]}$. Thus, atmospheric correction is essential to retrieve signals from the sea. The atmospheric correction for the images presented in this study is performed using default approach given in NASA SeaDAS 7.2. The atmospherically corrected images doesn't reveal any significant sun-glint effect, therefore no sun-glint correction is applied to the images. A fundamental challenge for remote sensing of coral reefs is the existence of the water column above the bottom features of interest (i.e., the benthic habitat) ${ }^{[27]}$.

The water column correction for the images presented in this study is performed using Lyzenga's 18 algorithm. This algorithm calculates the "depth invariant bottom index", which corrects for water column effect using pairs of multispectral bands instead of calculating bottom reflectance for each band. Lyzenga's algorithm is currently one of the most popular approaches for water column correction among others and the use of this methodology has resulted in increased mapping accuracy by digital classification processes [23].

\subsection{End-member Collection}

End-members are spectra that are chosen to represent pure surface materials in a spectral image. The End-members selected for Gulf of Mannar included sand, sea-grass, branched coral and massive coral. The characteristics of each end-member were based on measurements of in-situ data collected from various locations throughout the Gulf of Mannar in March-2017, August-2017 \& March-2018. Data were acquired using RAMSES-TriOS Hyperspectral radiometer ranges between the wavelengths of $350 \mathrm{~nm}-900$ $\mathrm{nm}$ at a bandwidth of $3 \mathrm{~nm}$ encased in a custom underwater housing. Individual reflectance measurements were grouped by species and substrate type and then consolidated into the components of sand, sea-grass, branched coral and massive coral. The spectral properties of individual coral reef species and its associated features in Gulf of Mannar were discussed by Kandasami Nimalan et al. Fig.3 shows the spectral characteristics of end-members considered in this study.

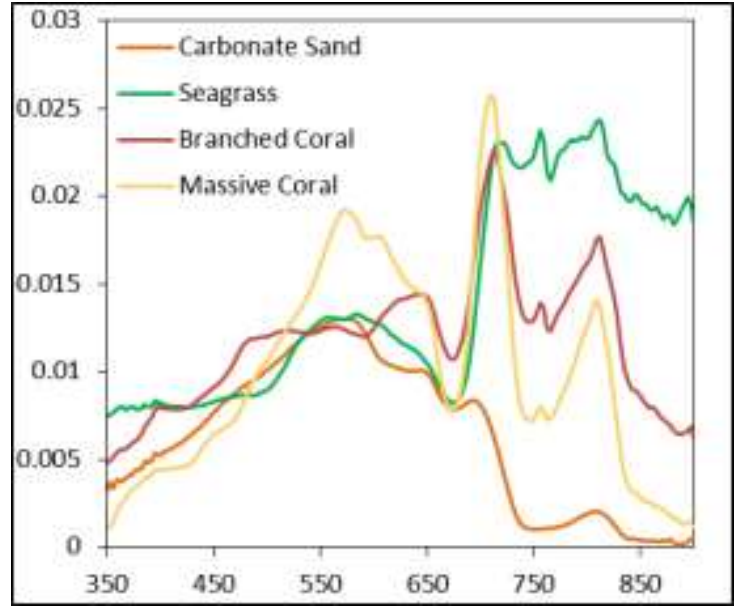

Fig 3: Spectral Signatures of Carbonate Sand, Sea-grass, Branched Coral and Massive Coral.

\subsection{Linear Spectral Unmixing}

Constrained linear unmixing model is used to achieve a classification of benthic composition. In spectral unmixing, each pixel in the image is assumed to be a linear combination of the selected spectral endmembers, where the fractional spectral contribution from each endmember is equivalent to the fractional spatial contribution of the corresponding reef component. The result of the unmixing is a measure of the membership of the individual endmember to the source spectrum. This measure is called the endmember's abundance. The unmixing algorithms are based on the following linear mixing model, which assumes that a spectrum is a linear superposition of end-members (https://seadas.gsfc.nasa.gov/help/).

$$
\begin{aligned}
& R_{k}=\sum_{i}^{n} a_{i} \cdot E_{i, j}+\varepsilon_{k} \\
& \text { RMSE }=\sqrt{ }\left(\sum_{k}^{m} \varepsilon_{k}^{2}\right)^{-m}
\end{aligned}
$$

$\mathrm{R}_{k}=$ Reflectance of source at wavelength $k$

$\mathrm{E}_{k, i}=$ Reflectance of endmember $i$ at wavelength $k$ $\mathrm{a}_{i}=$ Abundance of endmember $i$

$\varepsilon_{k}=$ Error at wavelength $k$

RMSE $=$ Root Mean Square Error of the $\varepsilon_{k}$

$N=$ Number of endmembers

$M=$ Number of the wavelengths in the discrete spectrum

\section{Results and Discussions}

The purpose of generating True Colour Composite (TCC) image is to resemble closely what would be observed by the human eyes. The TCC for the study area is generated with Landsat-8 images by assigning R-655 nm; G-561 nm; B-482 $\mathrm{nm}$ and is shown in Fig.4A.

In contrast to a true-colour image, a false-colour image sacrifices natural colour rendition in order to ease the detection of features that are not readily discernible. The display colour assignment for any band of an image can be done in an entirely arbitrary manner. In this case, the colour of a target in the displayed image does not have any resemblance to its actual colour. The choice of spectral bands is governed by the physical properties of the object under 
investigation. The False Colour Composite (FCC) image for this study is generated by assigning the R-1609 nm; G-2201 $\mathrm{nm}$; B-865 $\mathrm{nm}$ since the best wavelength region for discriminating land from water is the near-infrared and middle-infrared regions at wavelengths between $740-2500$ nm ${ }^{[16]}$ and is shown in Fig.4B. In this display scheme, the land and cloud portions are masked out and appears in grey colour, coral reefs in the study area appears on the bluish colour and water portion appears in black colour.

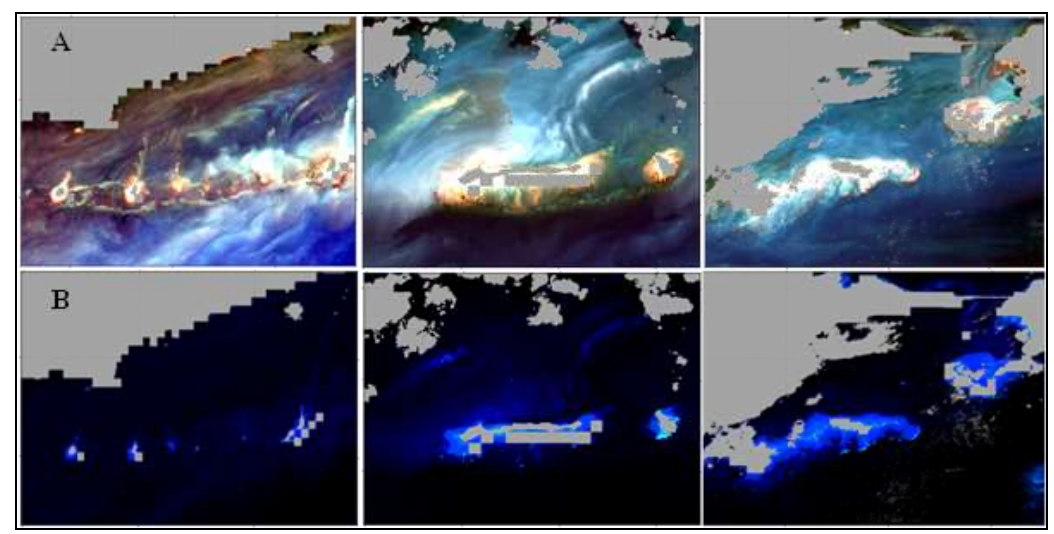

Fig 4: A, True Colour Composite Image of various islands represented in the study area; B, False Colour Composite Image of various islands represented in the study area.

\subsection{Spectral Unmixing}

Spectral Unmixing is the procedure by which the measured spectrum of a pixel is decomposed into a collection of spectral endmembers and a set of corresponding fractional abundances within the pixel ${ }^{[6,19,20]}$.

Spectral unmixing offers a fundamentally different habitat map product to a conventional per-pixel classification. A perpixel classification generates a single habitat map that identifies the dominant benthic component inside each pixel's field of view in accordance with its overall spectral properties, whereas an unmixing classification generates several maps depicting the relative contribution from each benthic component inside the study area ${ }^{[26]}$. Spectral unmixing results are highly dependent on the input endmembers; changing the endmembers leads to changes in the results. The number of endmembers must be less than the number of spectral bands and all of the endmembers in the image must be used. In this study, the number of spectral bands available is 5 (443 nm, $482 \mathrm{~nm}, 561 \mathrm{~nm}, 655 \mathrm{~nm} \& 865 \mathrm{~nm}$ ) and the number of endmembers considered is 4 (Carbonate Sand, Sea-grass, Branched Coral and Massive Coral). This satisfies the criteria of number of endmembers must be less than the number of spectral bands. The result produced using linear spectral unmixing technique is depicted in Fig. 5.

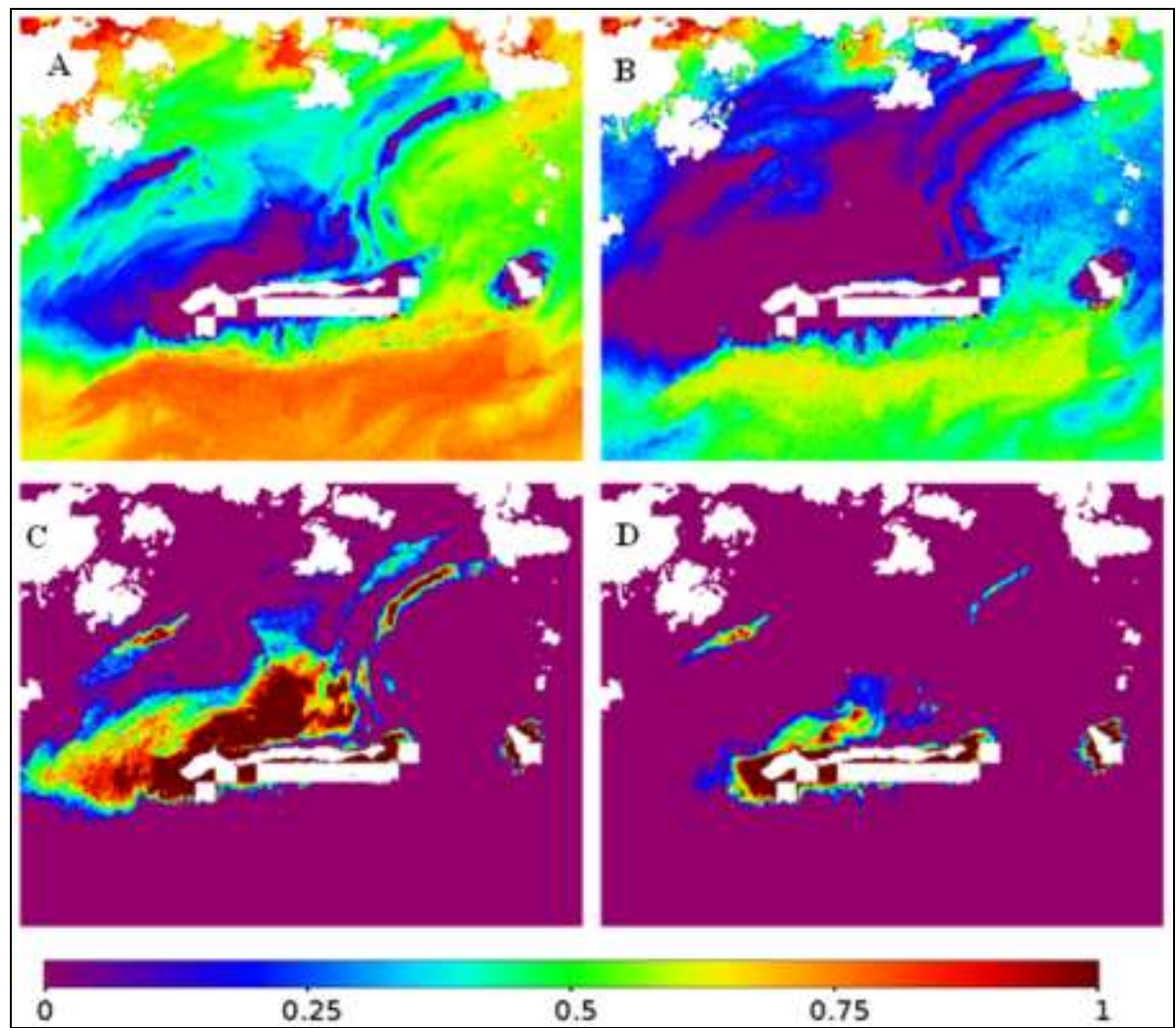

Fig 5: Fractional abundance of various benthic compositions; A, Sand; B, Sea-grass; C, Branched Coral; D, Massive Corals. 
The image is classified as four categories; category-A depicts the Fractional abundance of sand in corresponding study site; category-B depicts the Fractional abundance of sea-grass in corresponding study site; category-C depicts the Fractional abundance of branched corals in corresponding study site; and category-D depicts the Fractional abundance of massive corals in corresponding study site. Individually, each of these maps illustrates the distribution of a single component of the reef community, while together they represent the overall habitat composition.

In this display scheme, the land and cloud portions are masked out and land portions will be appears in grey colour and cloud cover will be appears in white colour. This kind of abundance maps provides information on habitat structure and composition at a local scale and as well as provides the estimates of habitat diversity. Also, this kind of mapping enables large-scale, multi-site mapping of coral reefs ${ }^{[3,25]}$. It can be observed that, the spatial distribution of branched coral is comparatively higher than the spatial distribution of massive corals. Areas at where, the spatial distribution of coral reef is dominant benthic coverage, those are the sites that are important and care must be taken for protection of those areas. Comparison of different benthic compositions provided the insight on processes that takes place with one other. In places where the fraction abundance of branched and massive corals is predominant (mostly around the islands) the fraction abundance of seagrass is null and vice versa.

\subsection{Ground Truth}

Field surveys were performed at March-2017, August-2017 \& March-2018 across the Gulf of Mannar Islands. A total of 7 control points were visited during the March-2017 (Concurrent to Landsat-8 Image Acquisition). Each point was located with the help of GPS co-ordinates and the benthic components present in the particular point (Sea-grass, Branched Coral and Massive Coral) were visually examined by group of experienced professionals. Fig.6 shows the field pictures of various benthic compositions present in GoM.

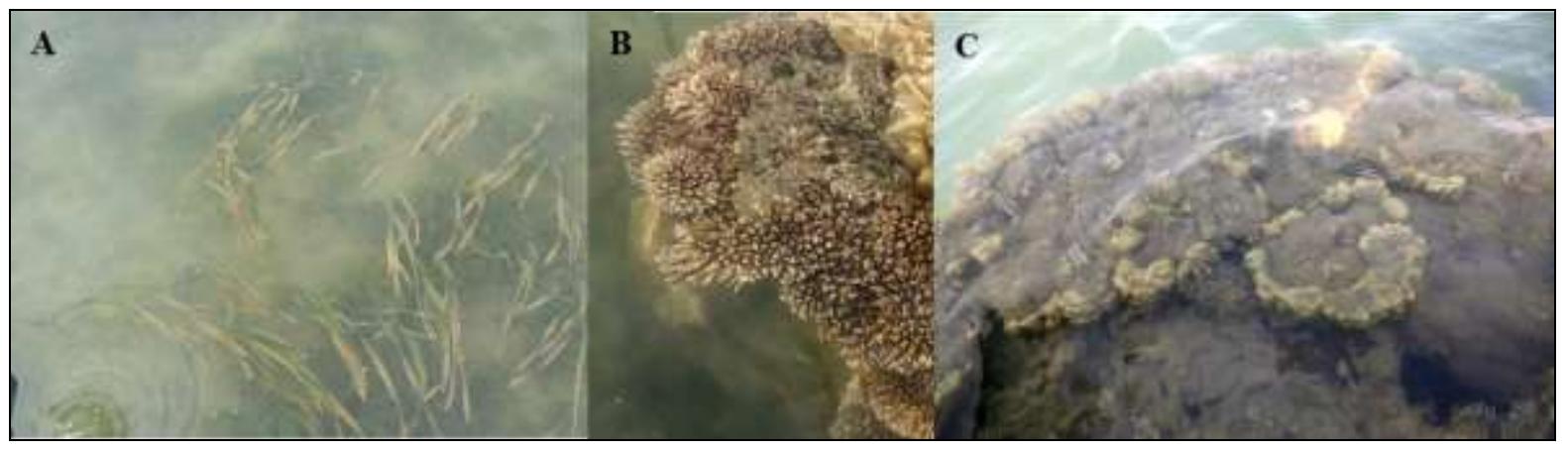

Fig 6: Field pictures of A, Sea-grass; B, Branched Corals; and C, Massive Corals.

\section{Conclusion}

This study provides the comprehensive way for assessing the abundance fraction of various benthic coverage's (sand, seagrass, branched corals and massive corals) using linear spectral unmixing analysis. The results can be utilised in a practical manner to generate estimates of the various components present in coral reef community. Such maps can also be used to characterize the landscape structure and composition of reefs, which can in turn be linked to environmental and human impacts. However, the broad width of these sensor's spectral bands limits accurate discrimination of more specific benthic features, since many biotic features (coral, seagrass and macroalgae) have similar reflectance characteristics, and it is suggested that hyperspectral sensors can better differentiate such features ${ }^{[13]}$. In turn, these kinds of remote sensing approaches are cost-effective and act as a valuable tool for the evaluation and periodical monitoring of coral reef community.

\section{Acknowledgements}

This work is supported by the Network Project on Imaging Spectroscopy and Applications (NISA), Interdisciplinary Cyber Physical Systems Division, Department of Science and Technology, Ministry of Science and Technology, Government of India, under grant BDID/01/23/2014HSRS/17 (WAT-V). The authors gratefully acknowledge U.S. Geological Survey (USGS) for providing Landsat 8 data and Ocean Biology Processing Group of NASA for distribution and support of the SeaDAS Software. The authors are grateful to Prof. Palanisamy Shanmugam, Department of Ocean Engineering, Indian Institute of Technology Madras, Chennai and his team for helping in collecting in-situ measurements.

\section{Conflict of interest}

On behalf of all authors, the corresponding author states that there is no conflict of interest.

\section{References}

1. Andréfouët S, Kramer P, Torres-Pulliza D, Joyce K, Hochberg E, Garza-Perez R, et al. Multi-site evaluation of IKONOS data for classification of tropical coral reef environments. Remote sensing of environment 2003;88(1-2):128-143.

2. Andréfouët S, Muller-Karger FE, Robinson JA, Kranenburg C, Torres-Pulliza D, Spraggins S, et al. Global assessment of modern coral reef extent and diversity for regional science and management applications: a view from space. In: Proceedings of the $10^{\text {th }}$ International Coral Reef Symposium, Okinawa, Japan 2004.

3. Andréfouët S, Muller-Karger FE, Robinson JA, Kranenburg CJ, Torres-Pulliza D, Spraggins SA, et al. Global assessment of modern coral reef extent and diversity for regional science and management applications: a view from space. In: Proceedings of $10^{\text {th }}$ international coral reef symposium 2006, 1732-1745.

4. Bahuguna A, Nayak S, Roy D. Impact of the tsunami and earthquake of $26^{\text {th }}$ December 2004 on the vital coastal ecosystems of the Andaman and Nicobar Islands assessed using RESOURCESAT AWiFS data". International Journal of Applied Earth Observation and Geoinformation 2008;10(2):229-237. 
5. El-Askary H, Abd El-Mawla SH, Li J, El-Hattab MM, El-Raey M. Change detection of coral reef habitat using Landsat-5 TM, Landsat 7 ETM+ and Landsat-8 OLI data in the Red Sea (Hurghada, Egypt)". Int. J. Remote Sens 2014;35:2327-2346.

6. Gebbinck MSK, Schouten TE. Decomposition of Mixed Pixels. In Satellite Remote Sensing II", International Society for Optics and Photonics: Bellingham, WC, USA 1995, 104-115.

7. Giardino C, Bresciani M, Fava F, Matta E, Brando VE, Colombo $\mathrm{R}$, et al. Mapping submerged habitats and mangroves of Lampi Island Marine National Park (Myanmar) from in situ and satellite observations". Remote Sens 2016;8(2).

8. Goodman JA, Ustin SL. Classification of benthic composition in a coral reef environment using spectral unmixing". Journal of Applied Remote Sensing 2007;1:116.

9. Hamylton S. Determination of the separability of coastal community assemblages of the Al Wajh Barrier Reef, Red Sea, from hyperspectral data. Central European Journal of Geosciences 2009;1,:95-105.

10. Hedley JD, Mumby PJ. A remote sensing method for resolving depth and subpixel composition of aquatic benthos". Limnology and Oceanography 2003;48:480488.

11. Hedley JD, Mumby PJ, Joyce E, Phinn S. Spectral unmixing of coral reef benthos under ideal conditions. Coral Reefs 2004;23:60-73.

12. Hedley JD, Roelfsema C, Brando V, Giardino C, Kutser T, Phinn S, et al. Coral reef applications of Sentinel-2: Coverage, characteristics, bathymetry and benthic mapping with comparison to Landsat- 8 ". Remote Sensing of Environment 2018;216:598-614.

13. Hochberg EJ, Atkinson MJ. Capabilities of remote sensing to classify coral, algae, and sand as pure and mixed spectra". Remote Sens Environ 2003;85:174-189.

14. Holden H, Ledrew E. Hyperspectral linear mixing based on in situ measurements in a coral reef environment". In International Geoscience and Remote Sensing Symposium, Toronto, ON, Canada 2002.

15. Ian Leiper, Stuart Phinn, Arnold G Dekker. Spectral reflectance of coral reef benthos and substrate assemblages on Heron Reef, Australia, International Journal of Remote Sensing 2012;33(12):3946-3965.

16. John R. Jensen. Remote sensing of water. In: Remote sensing of the Environment An Earth Resource Perspective". Second Edition, Pearson Custom Library 2014, pp. 417-457.

17. Jokiel PL, Rodgers KS, Brown EK, Kenyon JC, Aeby G, Smith WR, et al. Comparison of methods used to estimate coral cover in the Hawaiian Islands. Peer J 2015, $1-22$.

18. Kandasami Nimalan, Muniappan Thanikachalam, Tune Usha. Hyperspectral Signatures of Coral Reef Species and Bottom Types from Gulf of Mannar, India". Indian Journal of Geo-marine Sciences 2018. (in-press)

19. Keshava N, Mustard JF Spectral unmixing. IEEE Signal Process. Mag 2002;19:44-57.

20. Keshava N. A survey of spectral unmixing algorithms". Linc. Lab. J 2003;14:55-78.

21. Kutser T, Dekker AG, Skirving W. Modelling spectral discrimination of Great Barrier Reef benthic communities by remote sensing instruments. Limnology and
Oceanography 2003;48:497-510.

22. Lyzenga D. Passive remote sensing techniques for mapping water depth and bottom features". Appl. Opt 1978; 17:379-383.

23. Mumby PJ, Clark CD, Green EP, Edwards AJ. Benefits of water column correction and contextual editing for mapping coral reefs". Int. J. Remote Sens 1998;19:203210.

24. Pillai CSG. Coral reefs of India, their conservation and management". In: Marine Biodiversity: Conservation and management. CMFRI, Cochin 1996, pp.16-31.

25. Purkis SJ, Kohler KE, Riegl BM, Rohmann SO. The statistics of natural shapes in modern coral reef landscapes. J Geol 2007;115:493-508.

26. Sarah Hamylton. Estimating the coverage of coral reef benthic communities from airborne hyperspectral remote sensing data: multiple discriminant function analysis and linear spectral unmixing", International Journal of Remote Sensing 2011;32:24:9673-9690.

27. Yamano H. Multispectral applications. In: Goodman, J.A., Purkis, S.J., Phinn, S.R. (Eds.), Coral Reef Remote Sensing. Sf pringer, Dordrecht, 2013;3:51-78. 